\title{
A FORMAÇÃo dE PROFESSORES PARA A INSERÇÃo dA PRÁtICA AMBIENTAL: UM RELATO DE EXPERIẾNCIA
}

\author{
TEACHER EDUCATION FOR INCLUSION OF ENVIRONMENTAL \\ PRACTICE: AN EXPERIENCE REPORT \\ LA FORMACIÓN DEL PROFESORADO PARA LA INCLUSIÓN DE LA \\ PRÁCTICA AMBIENTAL: UN RELATO DE EXPERIENCIA
}

\author{
Ediane Machado Wollmann ${ }^{1}$ \\ Ana Paula Santos de Lima ${ }^{2}$ \\ Daniela Sastre Rossi ${ }^{3}$ \\ Félix Alexandre Antunes Soares ${ }^{4}$
}

\begin{abstract}
RESUMO: A Educação Ambiental (EA) é estabelecida como uma dimensão da educação e precisa ser trabalhada em todos os níveis de ensino. Além disso, deve ser considerada como uma educação política que permita aos cidadãos reivindicar seus direitos e deveres. Diante disso, este estudo apresenta a descrição de um Curso de Formação realizado com docentes da rede pública de ensino, que teve por objetivo auxiliá-los na inserção e prática da EA em uma perspectiva interdisciplinar. Esta pesquisa configura-se como um estudo de caso, com abordagem descritivo-qualitativa, realizada com professores de uma escola estadual no município de Santa Maria (RS). O Curso de Formação foi dividido em três etapas: 1) Apresentação e problematização; 2) Desenvolvimento, explanação de temas e metodologias; e 3) Elaboração de planos de aula. Os resultados obtidos demonstraram que os sujeitos habitualmente abordavam a EA em suas disciplinas, embora muitas vezes não soubessem como construir um trabalho interdisciplinar e dar continuidade a este. Por meio da capacitação, os docentes puderam ampliar suas percepções sobre EA, além de conhecer novas estratégias metodológicas (Metodologia da Problematização e Oficinas Temáticas) para auxiliá-los em suas práticas pedagógicas.
\end{abstract}

PALAVRAS-ChAVE: Educação ambiental. Curso de formação de professores. Metodologias.

ABSTRACT: Environmental Education (EE) is established as a dimension of education and should be addressed at all education levels. Furthermore, it should be considered as a policy education allowing citizens to claim their rights and duties. Thus, this study presents the description of a Formation Course conducted with teachers of a public school, which aimed to assist them to insert and practice the EA in an interdisciplinary perspective. This research is a case study with a descriptive-qualitative approach and was carried out with teachers from a state school in the city of Santa Maria - RS. The Formation Course was divided into three stages: 1) Presentation and questioning; 2) Development, explanation of topics and methodologies; 3) Preparation of lesson plans. The results showed that subjects used to work with the EE in their disciplines, but often did not know how to build an interdisciplinary work and continue this. Through the formation course the teachers were able to expand their

\footnotetext{
${ }^{1}$ Doutoranda e Mestra no Programa de Pós-graduação em Educação em Ciências: Química da Vida e Saúde da Universidade Federal de Santa Maria (UFSM) - Santa Maria-RS. Professora de Química no Instituto Federal de Educação Ciência e Tecnologia Farroupilha. E-mail: ediane.wollmanniifarroupilha.edu.br ou edianewollmann@gmail.com.

${ }^{2}$ Doutoranda e Mestra no Programa de Pós-graduação em Educação em Ciências: Química da Vida e Saúde da Universidade Federal de Santa Maria (UFSM) - Santa Maria-RS. E-mail: ana_paula.sm@ hotmail.

${ }^{3}$ Doutoranda e Mestra no Programa de Pós-graduação em Educação em Ciências: Química da Vida e Saúde da Universidade Federal de Santa Maria (UFSM) - Santa Maria-RS. E-mail: danisrossi@gmail.com.

${ }^{4}$ Doutor e Mestre em Ciências Biológicas (Bioquímica) pela Universidade Federal do Rio Grande do Sul (UFRGS). Professor Adjunto da Universidade Federal de Santa Maria (UFSM) - Santa Maria - RS. E-mail: felix@ufsm.br.

Recebido em:14/11/2014 - Aceito em: 15/12/2014
} 
perceptions of EE, and Know new methodological strategies (Problematization Methodology and Thematic Workshops) to help them in teaching.

KEYWORDS: Environmental education. Training course for teachers. Methodologies.

RESUMEN: La Educación Ambiental (EA) se ha establecido como una dimensión de la educación y debe ser abordado en todos los niveles de la educación. Además, se debe considerar una educación política para que los ciudadanos reclaman sus derechos y deberes. Así, este estudio presenta una descripción de un curso de formación realizado con los profesores de las escuelas públicas, que tenían como objetivo ayudarles en la inserción y la práctica de EA en una perspectiva interdisciplinaria. Esta investigación aparece como un estudio de caso, con enfoque descriptivo y cualitativo, realizado con los profesores en una escuela estatal en Santa Maria - RS. El curso de capacitación se dividió en tres etapas: 1) Presentación y cuestionamiento; 2) El desarrollo, la explicación de los temas y metodologías; y 3) el desarrollo de planes de lecciones. Los resultados mostraron que los sujetos por lo general se acercaron a EA en sus disciplinas, pero a menudo no saben cómo construir un trabajo interdisciplinario y continuar esto. Através de la capacitación, los maestros pudieron ampliar sus percepciones de EA, y conocer nuevas estrategias metodológicas (Metodología del Plan de Estudios y Talleres Temáticos) para ayudarles en su enseñanza.

PALABRAS CLAVE: educación ambiental. curso de formación de profesores. metodologías.

\section{INTRODUÇÃ̃o}

Atualmente, a situação global, no que tange às questões ambientais, vem passando por profundas modificações nas últimas décadas. Em decorrência dos sistemas de produção adotados pela sociedade para promover $\mathrm{o}$ atendimento às nossas próprias exigências $\mathrm{e}$ necessidades, nossa cultura de consumo dificulta a percepção integral dos efeitos colaterais decorrentes da arquitetura social constituída. Tais efeitos causados podem atingir os ecossistemas, gerando desequilíbrios em cadeia pelo entrelaçamento existente (e nem sempre explícito) da mecânica do meio ambiente (BRASIL, 2007). Assim, mesmo que seja empiricamente pouco observável, a ciência já consegue interligar os pontos e afirmar que estamos passando por um processo de crise ambiental global.

Nesse contexto, a Educação Ambiental (EA) se faz necessária e pertinente para sensibilizar e modificar as transformações ocorridas na sociedade contemporânea. Por isso, desenvolver uma conscientização para as questões que envolvem o meio ambiente é reivindicação constante das propostas curriculares em distintos níveis de ensino (CARVALHO, 2002). Acreditamos que não basta apenas promover a conscientização, mas esta pode ser o primeiro passo de uma sensibilização a ser realizada em longo prazo para que, após isso, os indivíduos possam modificar sua cultura e comportamento.

Ao trabalharmos com questões relacionadas ao meio ambiente devemos considerar os diversos autores do sistema educativo, o que significa o engajamento das distintas percepções de Educação Ambiental, os conhecimentos das áreas, a inserção da comunidade, a capacitação dos profissionais e, ainda, o apoio da universidade em uma perspectiva interdisciplinar, que permita o auxílio da inserção da Educação Ambiental naquele contexto (TRISTÃO, 2004). 
A interdisciplinaridade pode ser compreendida como sendo uma reciprocidade entre as disciplinas e as áreas do conhecimento (FAZENDA, 2008). Ainda de acordo com Ivani Fazenda (2008), a interdisciplinaridade é uma atitude, uma externalização de visão do mundo, uma visão holística. Apoiando-se no princípio de interdisciplinaridade para trabalharmos com a inserção da EA na escola, também chegamos à definição de transversalidade. Para Gallo (1999), esse termo pressupõe a integração global de várias ciências, caracterizando-se em uma concepção holística de sistemas de totalidade, não permitindo a existência de barreiras entre as disciplinas. O meio ambiente é um tema transversal apresentado pelos Parâmetros Curriculares Nacionais (PCNs), orientado para perpassar todas as disciplinas, tendo como eixo estruturador dessa orientação curricular a formação para a cidadania, a compreensão dos problemas sociais, locais, regionais e mundiais (BRASIL, 1997).

Comumente, quando vamos desenvolver um trabalho voltado à inserção da Educação Ambiental no ambiente escolar ou em algum outro contexto, nos deparamos com concepções restritas sobre o entendimento de meio ambiente dos indivíduos. Algumas pesquisas, como Wollmann et al. (2013), demonstram que, na escola, isso não é diferente, pois tanto professores quanto alunos possuem percepções que se assemelham ao se tratar das questões envolvendo o ambiente. Por isso, destacamos, neste estudo, a importância da inserção de cursos de formação continuada para professores no sistema educativo, que proporcionem aos eles a ampliação de seus conhecimentos, aquisição de novas informações e a busca por uma metodologia eficaz para sua prática docente.

Para que o professor assuma sua responsabilidade de agente transformador, existe a necessidade de sua capacitação. A formação do professor deve ocorrer desde o início da sua inserção no Curso (formação inicial) e se estender por toda a sua trajetória docente (formação continuada). Para Freire (2000), a formação se dá pela problematização da realidade, reflexão e diálogo.

Na obra Formação de professores no Ensino de Ciências: tendências e inovações, de Carvalho e Gil-Pérez (2011), os autores destacam algumas necessidades formativas que o professor de Ciências deve possuir, como a ruptura de visões simplistas no ensino, pois, muitas vezes, os professores não conseguem relacionar os conceitos da sua disciplina com as contribuições da pesquisa e da inovação didática, gerando uma imagem espontânea do ensino. Nesse sentido, se já existe uma dificuldade dos docentes em relacionar a sua ciência com a pesquisa e as inovações da educação, é inevitável que eles encontrem dificuldades em buscar inter-relações com outras áreas e disciplinas.

Diante disso, nos questionamos de que maneira poderíamos inserir a EA em uma escola de educação básica, aliada aos princípios de interdisciplinaridade e transversalidade. Para isso, buscamos trabalhar a formação continuada de professores para que estes 
conseguissem construir coletivamente um trabalho que envolvesse o tema transversal meio ambiente. Por conseguinte, este estudo tem por objetivo apresentar uma descrição do curso que foi realizado com professores das séries finais do Ensino Fundamental, bem como discutir e analisar as contribuições desse tipo de intervenção para a inserção da EA naquele contexto escolar.

\section{METODOLOGIA}

Este trabalho faz parte de uma pesquisa, que se configura como um estudo de caso, realizada em uma escola da rede pública de ensino do município de Santa Maria, localizado na região central do estado do Rio Grande do Sul. Foram os sujeitos participantes desta pesquisa 11 professoras de distintas áreas, atuantes nas séries finais do Ensino Fundamental, bem como no nível médio e na modalidade de Educação para Jovens e Adultos (EJA). Esta pesquisa iniciou-se em março de 2013, por livre consentimento dos sujeitos envolvidos, e continua sendo realizada até o presente momento. Apresentaremos, neste trabalho, os resultados de um Curso de Formação ocorrido em junho de 2014 com as professoras desse contexto escolar.

Este estudo possui uma abordagem predominantemente qualitativa e, de acordo com os seus objetivos, um caráter descritivo, pois busca registrar e correlacionar os fenômenos estudados (SEVERINO, 2007). Utilizamos como instrumentos de análise: uma entrevista não diretiva; construção de planos de aula e aplicação de um questionário. Os dados foram analisados por meio da metodologia Análise de Conteúdo, proposta por Bardin (2011).

Primeiramente foi estendido um convite para todos os professores da escola para participar de um Curso de Formação intitulado "Educação Ambiental - Perspectivas e Desafios". As professoras foram liberadas em dois turnos (manhã e tarde) para comparecerem na formação, totalizando oito horas de intervenção (Tabela 1).

TABELA 1 - Etapas do desenvolvimento do Curso de Formação

\begin{tabular}{cl}
\hline $\mathbf{1}^{\text {a Etapa }}$ & $\begin{array}{l}\text { Apresentação e problematização com todos os } \\
\text { participantes. Entrevista não diretiva. }\end{array}$ \\
$\mathbf{2}^{\text {a Etapa }}$ & $\begin{array}{l}\text { Explanação das percepções de EA e meio ambiente, } \\
\text { conceitos e definições de interdisciplinaridade, } \\
\text { transversalidade, metodologias, temáticas ambientais e } \\
\text { vídeos. }\end{array}$ \\
$\mathbf{3}^{\text {a Etapa }}$ & Desenvolvimento dos planos de aula e discussão. \\
\hline Avaliação do Curso & Aplicação de um questionário \\
\hline
\end{tabular}

Fonte: Elaborada pelos autores 
No início da intervenção, as professoras foram convidadas a se apresentar ao grupo, relatarem o seu tempo de profissão na escola e se costumavam trabalhar com a Educação Ambiental desde a sua formação. Esse momento teve duração de uma hora e meia, em que conseguimos relacionar a vivência dos sujeitos com os assuntos que seriam discutidos no decorrer do curso por meio de uma entrevista não diretiva. A escolha desse instrumento de análise ocorreu porque nesse tipo de entrevista colhem-se informações dos sujeitos a partir de seu discurso livre, praticando, dessa forma, um diálogo descontraído, dando liberdade para o participante expressar sem constrangimentos suas representações (SEVERINO, 2007).

A problematização ocorreu por meio da discussão sobre o que entendemos por Educação Ambiental e meio ambiente. Para isso, apresentamos imagens por um projetor multimídia, com diferentes tipos de ambiente, e questionamos qual delas melhor representaria o que nossos alunos entendem como sendo o meio ambiente e por quê. Além disso, discutimos com as professoras as distintas correntes sobre a EA existentes na literatura. Para finalizar essa etapa, lançamos o seguinte problema: Como podemos inserir a EA no ambiente escolar de uma maneira significativa e condizente com as orientações das Diretrizes Curriculares? (BRASIL, 2013).

Depois de lançado o problema, partimos para a segunda etapa do curso, na qual discutimos os conceitos de interdisciplinaridade, transversalidade, orientações dos documentos governamentais e apresentamos dois tipos de metodologias de ensino que poderiam auxiliar os professores na inserção das questões ambientais: Oficina Temática (MARCONDES, 2008) e Metodologia da Problematização (BERBEL, 1998). Nesse momento, explicamos cada etapa das respectivas metodologias e entregamos aos sujeitos textos referentes a estudos de autores que utilizaram tais metodologias para trabalhar em sala de aula.

Após realizarmos um intervalo, retornamos com as discussões abordando algumas temáticas ambientais que poderiam ser desenvolvidas na escola, dependendo do contexto, tais como: sustentabilidade; política e legislação ambiental; resíduos; reciclagem; reutilização; agrotóxicos e alimentos; entre outras. Então, apresentamos vídeos problematizadores utilizados como uma ferramenta didática para o professor abordar a Educação Ambiental em sala de aula. Além disso, mostramos alguns sites que trazem o tempo real de consumo da população mundial.

$\mathrm{Na}$ terceira etapa do Curso de Formação, apresentamos um modelo de plano de aula e discutimos com as professoras como poderíamos elaborar aulas interdisciplinares que envolvessem o tema transversal meio ambiente, bem como metodologias que auxiliassem essa inclusão. Todas as professoras receberam os modelos de plano de aula, e nós dividimos os participantes em dois grupos: seis participantes constituíram o grupo 1 e cinco, o grupo 2 . Propusemos a cada grupo que elaborassem coletivamente um planejamento de aula interdisciplinar voltado à Educação Ambiental. Vale salientar que, embora o curso tenha dado 
suporte teórico para os sujeitos, a escolha de metodologias, temas ou qualquer outra forma de planejamento foi livre.

Após a construção dos planejamentos, cada grupo apresentou a sua proposta, ocorrendo a troca de experiências entre os dois grupos. Para averiguarmos se esse tipo de intervenção auxiliou os docentes em sua formação, um mês depois, foi aplicado um questionário com as seguintes questões abertas:

1) Você considera importante participar de Cursos de Formação?

2) Como você está trabalhando a Educação Ambiental (EA) em suas aulas? Ocorreu alguma mudança após a sua participação no Curso de Formação?

3) Com relação à capacitação em EA que realizamos, suas expectativas foram superadas? Aponte aspectos positivos e negativos que considere importantes.

A seguir, apresentamos a análise dos resultados obtidos nesse estudo.

\section{RESULTADOS E DISCUSSÕES}

Os resultados foram analisados por intermédio da Análise de Conteúdo. De acordo com Bardin (2011), essa metodologia trata de compreender criticamente o sentido manifesto ou oculto das comunicações, envolvendo, portanto, a análise do conteúdo das mensagens, os enunciados dos discursos, bem como a busca dos significados dessas mensagens.

Detectou-se que todos os participantes deste estudo são do sexo feminino. Das 11 professoras que participaram da pesquisa: duas são da disciplina de Português; uma de Matemática, uma de Ciências e Matemática; duas de Geografia; uma de História; uma de Educação Física; uma de Artes; uma Orientadora Educacional e uma de Ciências e Química. Para uma melhor compreensão dos resultados, identificamos os sujeitos participantes por meio das seguintes representações, conforme a Tabela 2:

TABELA 2 - Identificação dos participantes da pesquisa

\begin{tabular}{rll}
\hline & Participantes & Representação \\
\hline 1. & Professora de Português & $\mathrm{P} 1$ \\
2. & Professora de Português & $\mathrm{P} 2$ \\
3. & Professora de Matemática & $\mathrm{P} 3$ \\
4. & $\begin{array}{l}\text { Professora de } \\
\text { Ciências/Matemática }\end{array}$ & $\mathrm{P} 4$ \\
\hline
\end{tabular}




\begin{tabular}{|llc}
\hline 5. & Professora de Geografia & P5 \\
\hline 6. & Professora de Geografia & P6 \\
\hline 7. & Professora de História & P7 \\
\hline 8. & $\begin{array}{l}\text { Professora de Educação } \\
\text { Física }\end{array}$ & P8 \\
\hline 9. & Professora de Artes & P9 \\
\hline 10. & $\begin{array}{l}\text { Pedagoga/Orientadora } \\
\text { Educacional }\end{array}$ & P10 \\
\hline 11. & $\begin{array}{l}\text { Professora de } \\
\text { Ciências/Química }\end{array}$ \\
\hline
\end{tabular}

Fonte: Elaborada pelos autores

\subsection{Descrição e Análise da entrevista não diretiva}

Todas as professoras se apresentaram e relataram tanto o seu tempo de experiência docente total quanto o tempo de carreira no magistério, bem como sua trajetória naquela escola. Observou-se que o tempo médio que as professoras lecionam nesse contexto escolar é de 3,5 anos, variando de 1 a 9 anos aproximadamente, e a experiência docente no magistério varia de 4 a 20 anos.

Inicialmente, ao serem questionadas sobre como inseriam a Educação Ambiental em suas aulas e se costumavam fazer isso, todas as professoras, em algum momento, afirmaram que já trabalharam com a EA em sua disciplina. Embora algumas professoras admitiram realizar essa inserção em outras escolas e não propriamente a deste estudo. A seguir, categorizamos e quantificamos (Tabela 3) as principais estratégias e instrumentos utilizados pelas professoras para incluírem o tema meio ambiente em suas aulas, sendo que algumas convencionaram se apropriar de vários instrumentos pedagógicos.

TABELA 3 - Estratégias e instrumentos utilizados para inserção da EA antes do curso

\begin{tabular}{cccc}
\hline Estratégias & Instrumentos & $\begin{array}{c}\text { Número de } \\
\text { professoras } \\
\text { que } \\
\text { utilizam }\end{array}$ & Professoras envolvidas \\
\hline $\begin{array}{c}\text { Relação com } \\
\text { conteúdos } \\
\text { em aula }\end{array}$ & Livros didáticos & 2 & P4; P11 \\
Projetos & $\begin{array}{c}\text { Pesquisas; } \\
\text { interpretação de } \\
\text { charges; discussão } \\
\text { de textos e vídeos } \\
\text { Interpretação de } \\
\text { gráficos; discussão } \\
\text { de textos e debates }\end{array}$ & 5 & P1; P2; P6; P7 e P8 \\
\hline Assunto/tema & 4 & P3; P5; P9 e P10 \\
\hline
\end{tabular}

Fonte: Elaborada pelos autores 
Das 11 professoras participantes, $2(18,18 \%)$ relataram que costumavam trabalhar com questões ambientais através da relação de proximidade dos conteúdos científicos com o tema (P4 e P11). Além disso, essas mesmas professoras citaram que costumam utilizar como ferramenta o Livro Didático. Percebemos que a abordagem do tema meio ambiente é mais centrada no conteúdo de ecologia da disciplina de Ciências, não ocorrendo muitas vezes correlações com outros conteúdos e áreas do conhecimento. O foco de uma educação voltada ao novo paradigma ambiental deveria compreender, além de um ecossistema natural, um espaço de relações socioambientais, que foram configuradas por conflitos sociais (CARVALHO, 2001).

Pela entrevista, observamos que cinco professoras $(45,45 \%)$ enfatizaram já terem trabalhado com a Educação Ambiental por meio de projetos mais específicos e algumas delas citaram a Agenda 21, um projeto orientado pelo Governo Federal desde o ano de 2001, tendo por objetivo propiciar a conscientização socioambiental da comunidade escolar com atividades educativas que visam à importância da preservação do Planeta Terra (BRASIL, 2001). Buscando alcançar os objetivos do Projeto, os sujeitos costumavam utilizar como instrumentos pedagógicos pesquisas em que os estudantes deveriam buscar por conta própria o seu conhecimento em charges, textos e vídeos, sendo estes mais utilizados pelas professoras da disciplina de Português.

Nesse sentido, observamos que o projeto foi desenvolvido na escola no decorrer de 2013, entretanto, algumas professoras reclamaram da falta de continuidade dele após a saída de uma professora que coordenava tais atividades. De acordo com estudos de Narcizo (2009), implementar a Educação Ambiental nas escolas tem se mostrado uma tarefa difícil, visto que existem muitos obstáculos nas atividades de sensibilização e formação, na implantação de atividades e projetos e na manutenção e continuidade dos que já existem. Corroborando com o que diz a autora, acreditamos que a Educação Ambiental não pode ocorrer por meio de atividades pontuais, mas sim por uma mudança de paradigma que exige uma reflexão e apropriação de valores.

Outra estratégia que apareceu no discurso dos sujeitos foi a utilização de um assunto/tema para trabalhar com a EA (36,36\%). Observamos que esses sujeitos utilizavam como instrumentos pedagógicos interpretação de gráficos, discussão de textos e debates, os quais eram utilizados individualmente dentro da disciplina, visando sempre à grade curricular.

Percebemos durante a entrevista que, embora as professoras costumassem trabalhar com a Educação Ambiental, elas, em alguns momentos, admitiam ter dificuldades e inseguranças para trabalhar com essa dimensão dentro de uma perspectiva mais ampla e interdisciplinar. Isso pode ser justificado pela formação inicial que essas professoras tiveram ou, ainda, pela pouca formação continuada. 
Os Parâmetros Curriculares Nacionais (PCNs) apresentam as dificuldades encontradas pelos professores para trabalhar os temas transversais, pois sua formação tradicional, muitas vezes, não contempla a visão política ou trata das questões sociais, centrando-se mais no conhecimento de conteúdos e no trabalho educativo (BRASIL, 1998b). As principais dificuldades demonstradas pelos participantes para inserirem a Educação Ambiental foram: falta de conhecimento sobre temas; pouco tempo para preparar as aulas; dificuldade de trabalhar de forma interdisciplinar.

Nesse contexto, algumas professoras relataram ser mais produtivo quando o trabalho em Educação Ambiental é realizado em escolas de municípios menores, onde existe um maior incentivo tanto dos órgãos públicos municipais quanto um maior envolvimento da comunidade escolar (pais e família). Essas professoras salientaram que no município de Santa Maria, por exemplo, não existe um adequado processo de separação do lixo por parte da Prefeitura. Portanto, embora se faça um trabalho de conscientização com os alunos, a realidade não contribui para se efetivar atitudes ambientalmente corretas. Nesse sentido, de acordo com a Lei $\mathrm{n}^{\circ} 12.305$, em seu Art. $10^{\circ}$, que trata da Política Nacional de Resíduos Sólidos, encontramos que cabe ao Distrito Federal e aos Municípios a gestão integrada dos resíduos sólidos gerados nos respectivos territórios, bem como é de responsabilidade do gerador o gerenciamento de resíduos (BRASIL, 2010).

Diante disso, acreditamos que existe a necessidade de se incrementar os meios e a acessibilidade à informação como caminhos possíveis para modificar o quadro atual de crise ambiental. Ao promover a consciência ambiental, expande-se a possibilidade de a comunidade participar dos processos decisórios da sociedade, atuando como cidadão crítico (TRISTÃO, 2004).

\subsection{Descrição e Análise dos planos de aula}

Após serem realizadas a problematização, a discussão e a capacitação no curso, as professoras, em grupos, elaboraram um modelo de plano de aula, que se tornou um planejamento para ser inserido naquele ambiente escolar. Ocorreu a formação de dois grupos que utilizaram metodologias e públicos distintos, conforme Tabela 4: 
TABELA 4 - Planejamento dos Grupos

\begin{tabular}{|c|c|c|}
\hline & GRUPO 1 & GRUPO 2 \\
\hline $\begin{array}{c}\text { Tema } \\
\text { escolhido }\end{array}$ & Sustentabilidade & Sustentabilidade \\
\hline Metodologia & Oficina temática & $\begin{array}{l}\text { Problematização: } \\
\text { Arco de Maguerez }\end{array}$ \\
\hline Público-alvo & $6^{\circ}, 7^{\circ}$ e $8^{\circ}$ anos & $8^{\circ}$ e $9^{\circ}$ anos \\
\hline Período & $\begin{array}{c}\text { Março a } \\
\text { Novembro de } 2014\end{array}$ & $\begin{array}{c}\text { Julho a Novembro } \\
\text { de } 2014\end{array}$ \\
\hline $\begin{array}{l}\text { Professoras } \\
\text { responsáveis }\end{array}$ & $\begin{array}{c}\text { P1; P3; P4; P6; P8 } \\
\text { e P11 }\end{array}$ & $\begin{array}{c}\text { P2; P5; P7; P9 e } \\
\text { P10 }\end{array}$ \\
\hline
\end{tabular}

Observou-se que ambos os Grupos optaram por abordar o mesmo tema. De acordo com Tristão (2004), o tema Sustentabilidade confronta-se com a "sociedade de risco" que vivenciamos, portanto, isso requer a necessidade de uma multiplicação das práticas sociais, baseadas no acesso à informação e à educação ambiental em uma perspectiva integradora.

\subsection{Plano de aula do Grupo 1}

O Grupo 1 constituiu-se por professores das disciplinas de Português, Matemática, Ciências, Geografia, Educação Física e Química, optando estes por abordar o tema "sustentabilidade". Os participantes do grupo desenvolveram um modelo de plano de aula que seguisse a metodologia de uma Oficina Temática. Os sujeitos deram continuidade ao Projeto Agenda 21 em que estavam trabalhando desde o ano anterior na escola, mas que se encontrava estagnado.

A oficina temática pode representar um local de trabalho, no qual se buscam soluções para um problema a partir dos conhecimentos práticos e teóricos (MARCONDES, 2008). A seguir, encontram-se as principais características de uma Oficina Temática, segundo Marcondes (2008):

$\checkmark$ Utilização da vivência dos alunos e dos fatos do dia a dia para organizar o conhecimento e promover a aprendizagem;

$\checkmark$ Abordagem de conteúdos de Química e Ciência a partir de temas que sejam relevantes, permitindo, assim, a contextualização do conhecimento;

$\checkmark$ Participação ativa do estudante na elaboração do seu conhecimento.

As professoras definiram, no plano de aula, dar continuidade a algumas atividades que vinham sendo realizadas, incorporando a metodologia de oficinas temáticas, a fim de buscar a conscientização dos alunos e comunidade escolar sobre os prejuízos que os resíduos de sabonetes podem causar ao meio ambiente. Sendo assim, o planejamento foi desenvolvido 
para prosseguir durante todo o ano de 2014. A seguir, apresentamos a transcrição de uma parte do plano de aula do Grupo 1:

\begin{abstract}
Primeiramente ocorreu a exposição do tema e dos conteúdos relacionados. Durante esse período os alunos arrecadarão sobras - resíduos de sabonetes que serão utilizados na fabricação de sabonetes reciclados pelos mesmos. A fabricação do sabonete ocorrerá com as turmas por meio de oficinas temáticas planejadas com todas as professoras e orientadas pela professora de Química. Após a confecção do sabonete, os mesmos serão utilizados nas comemorações festivas da escola, como: aniversário da escola, festa junina, entre outras.
\end{abstract}

Constatamos, no plano de aula elaborado, que os alunos seriam avaliados pela participação durante todo o processo de realização (coleta e produção) dos sabonetes, incluindo o entendimento dos conteúdos (por meio de trabalhos, exercícios, teatros e outras avaliações), fabricação do sabonete e conscientização. Os recursos que serão utilizados para o desenvolvimento das aulas de acordo com o plano são os seguintes: quadro negro; internet e vídeo; jornais e revistas; material para confecção dos sabonetes.

Nesse aspecto, consideramos importante que os docentes busquem avaliar a aprendizagem dos alunos durante todo o processo, pois a avaliação é uma tarefa complexa que não se resume apenas na atribuição de notas no final; deve-se acompanhar passo a passo o processo de ensino-aprendizagem do educando (LIBÂNEO, 1994).

Pela análise do plano de aula, observamos que existe uma preocupação por parte das professoras em continuar com algumas estratégias e instrumentos pedagógicos que já vinham sendo utilizados por elas, resgatando os objetivos do Projeto Agenda 21, bem como buscando inserir em seus planejamentos uma nova metodologia de aula desenvolvida no Curso de Formação.

A metodologia baseada em oficinas temáticas permite a contextualização dos conteúdos e proporciona uma reflexão sobre o tema proposto. Nesse tipo de metodologia, o "oficineiro" (aquele que pratica a oficina) possui liberdade para eleger seus temas de estudo, suas fontes de pesquisa, além de poder reunir-se em um local que acredite ser mais adequado para a realização do trabalho.

\title{
3.4 Plano de aula do Grupo 2
}

O Grupo 2 foi constituído por professoras das disciplinas de Português, Geografia, História, Artes e uma Orientadora Educacional. Assim como o Grupo 1, os sujeitos optaram por abordar o tema "sustentabilidade", dando ênfase para o reaproveitamento de resíduos sólidos. As professoras desse Grupo desenvolveram o plano com o objetivo de conscientizar os alunos sobre a importância da reutilização dos resíduos para que assim houvesse uma mudança de postura relativa às questões ambientais. A estratégia escolhida pelos participantes para a abordagem do tema foi a Metodologia da Problematização: Arco de Charlez Maguerez, também discutida no decorrer do Curso de Formação. 
A metodologia da Problematização pode ser definida como uma estratégia de ensino, proposta curricular ou, ainda, proposta pedagógica (BERBEL, 1998). Essa metodologia parte de um problema observado da realidade para que no fim se volte a essa realidade intervindo com alguma solução (DIAZ BORDENAVE; PEREIRA, 2002). O desenvolvimento do Arco de Maguerez se faz por meio de cinco etapas, de acordo com a Figura 1:

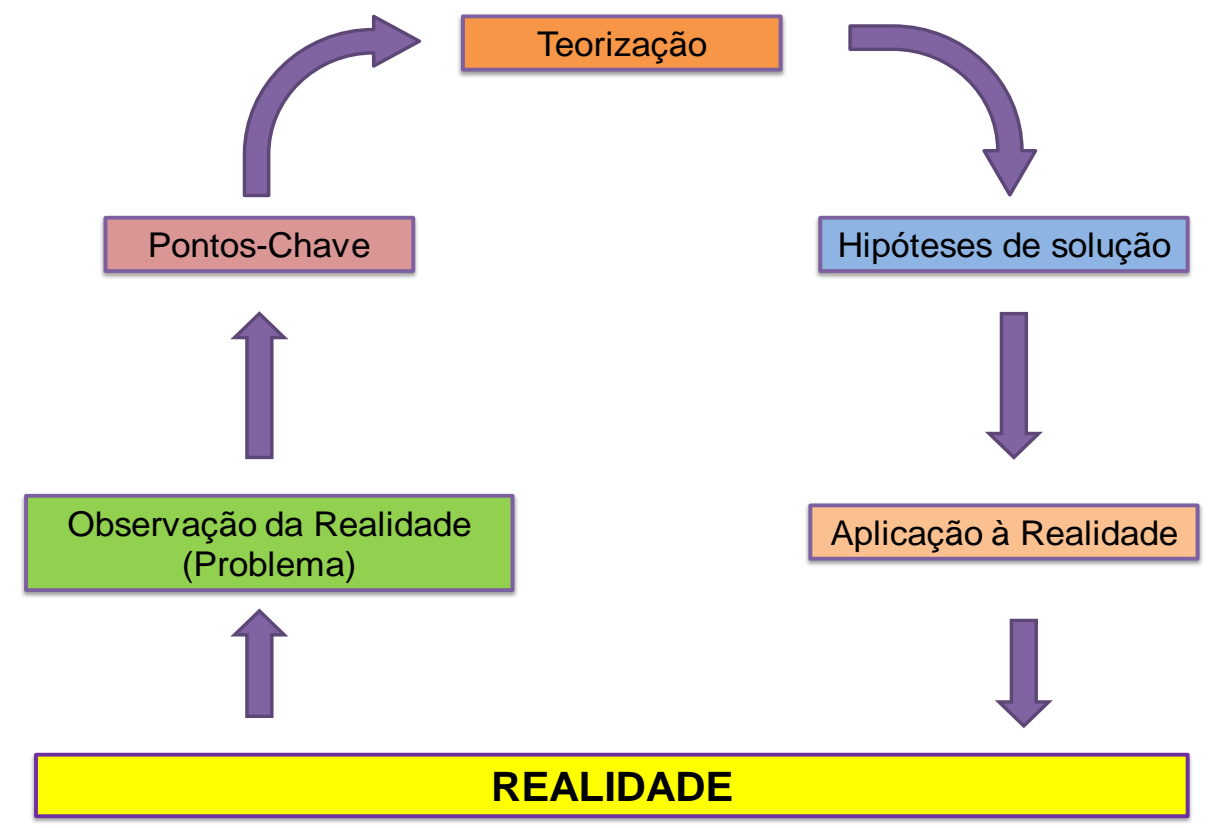

FIGURA 1 - Etapas da metodologia do Arco

(Adaptado de GARCIA et al., 2009)

Na primeira etapa (Observação da Realidade) é importante que o professor oriente seus alunos a observarem atentamente e a registrarem o que percebem sobre a realidade a ser estudada. Nesse sentido, as professoras definiram no plano que a realidade a ser observada poderia ser o não aproveitamento de resíduos que ocorria no cotidiano dos alunos, justificado, muitas vezes, pela falta de informação e conhecimento desses sujeitos a respeito do tema. Além disso, a realidade observada poderia partir da questão cultural e da acomodação de todos os sujeitos envolvidos com relação ao recolhimento e ao reaproveitamento dos resíduos sólidos.

Partindo para a segunda etapa (Pontos-Chave), as possíveis causas do problema deverão ser encontradas. Por isso, esse momento exige reflexão para a delimitação dos pontos a serem estudados. Nessa etapa as professoras planejaram trabalhar com o uso de textos sobre resíduos e rejeitos, da análise de charges e imagens sobre o tema e da apresentação do trabalho do artista Vick Muniz (sobre o lixão no Rio de Janeiro), além da interpretação de gráficos e tabelas.

$\mathrm{Na}$ terceira etapa (Teorização), os alunos precisam procurar entender o problema, organizarem-se em busca de respostas. Por isso, para esse momento, as professoras \begin{tabular}{l|l|l|l|l|l|l|} 
(C) ETD - Educ. temat. digit. & Campinas, SP & v.16 & n.3 & p.532-550 & set./dez. 2014 & ISSN 1676-2592 \\
\hline
\end{tabular} 
planejaram que os alunos fizessem uma pesquisa bibliográfica e uma entrevista em casa com seus familiares questionando-os sobre a "produção do lixo" (como separar o lixo; reciclar; reutilizar). Além disso, promoveriam uma palestra sobre resíduos com pesquisadores da Universidade Federal de Santa Maria para discutir o tema com os estudantes dos $8^{\circ}$ e $9^{\circ}$ anos.

Na quarta etapa (Hipóteses de Solução), os alunos deverão se questionar sobre o que é possível fazer para solucionar o problema. Diante disso, as professoras sugeriram a confecção de cartazes e fôlderes pelos estudantes para serem distribuídos na comunidade.

Já na quinta e última etapa (Aplicação à Realidade), os sujeitos envolvidos devem levar uma resposta de seus estudos, das suas compreensões para o problema observado. Sendo assim, para essa etapa, as professoras propuseram no plano de aula uma caminhada no Bairro para a entrega dos fôlderes contendo as informações sobre o tema. Outra proposta presente no planejamento foi a possível criação de um ponto de coleta de lixo eletrônico na escola.

A Metodologia da Problematização proporciona um ensino diferenciado do paradigma tradicional, permite que o aluno busque por conta própria soluções, desenvolvendo desta forma o seu raciocínio crítico (BERBEL, 1998).

Diante desse planejamento, constatamos que as professoras se engajaram na busca para a inserção da Educação Ambiental observando a realidade daquele contexto. Como observado, os dois grupos se propuseram a abordar um tema amplo que requer uma visão holística e um trabalho interdisciplinar incluindo os novos conhecimentos adquiridos no decorrer do curso.

Este é considerado um aspecto interessante, pois, embora se tenha divido em grupos para a construção dos planos, eles optaram por um tema em comum e partem da mesma realidade (reaproveitamento de resíduos) para iniciar a problematização. Entretanto, cada grupo elegeu uma metodologia distinta para desenvolver o planejamento, o que torna exclusivo o trabalho de cada um, podendo, assim, após a sua aplicação, considerarmos os aspectos vantajosos e desvantajosos de cada metodologia. Além de elaborar o planejamento, visamos que o mesmo fosse aplicado na escola de maneira permanente, sob orientação dos pesquisadores.

Na oficina temática, o professor pôde propor um tema, direcionar estratégias e fontes de pesquisa de acordo com o cotidiano do aluno. Na metodologia da Problematização, embora o professor também possa propor aos estudantes temas a serem estudados, são estes que irão buscar por conta própria maneiras de resolver o problema que eles mesmos observaram, ou seja, nosso planejamento e desenvolvimento de estratégias poderão mudar a qualquer momento. Além disso, na Metodologia da Problematização, os sujeitos deverão no final retornar aquela realidade para direcionar uma possível solução. Embora as duas metodologias apresentem diferentes etapas de desenvolvimento do trabalho, ambas

\begin{tabular}{l|l|l|l|l|l|l|} 
(C) ETD - Educ. temat. digit. & Campinas, SP & v.16 & n.3 & p.532-550 & set./dez. 2014 & ISSN 1676-2592 \\
\hline
\end{tabular}


apresentam-se como excelentes estratégias metodológicas que permitem a inserção da Educação Ambiental de forma interdisciplinar no ensino.

\subsection{Análise do Questionário}

Após o período de um mês, foi aplicado um questionário com as professoras da escola a fim de averiguar se o Curso de Formação alcançou suas metas pretendidas, sendo estas:

- Auxiliar os professores na inserção da Educação Ambiental em uma perspectiva interdisciplinar e transversal naquele contexto escolar;

- Abordar e discutir conhecimentos e informações sobre a dimensão ambiental, bem como sobre novas metodologias de ensino;

- Elaborar um modelo de plano de aula que permitisse os objetivos mencionados anteriormente.

Ao serem questionadas se consideravam importante participar de Cursos de Formação, todos os sujeitos afirmaram que sim. Além disso, alguns docentes frisaram que poderia existir mais tempo destinado a essas atividades, pois proporciona um momento de aprendizado para o professor que vive muitas vezes na correria da sala de aula, como pode ser observado nos seguintes relatos transcritos: "Considero muito importante, pois é um momento que nós também aprendemos e que muitas vezes não conseguimos buscar estas pesquisas por falta de tempo (P5)". "Sim é importante. Deveriam existir mais Cursos como este que nos ajudou a trabalhar de maneira interdisciplinar (P11)".

Com relação à segunda pergunta do questionário: "Como você está trabalhando a Educação Ambiental (EA) em suas aulas? Ocorreu alguma mudança após a sua participação no Curso de Formação?" Categorizamos as principais maneiras de inserção da EA apresentadas nos relatos dos docentes, de acordo com a Tabela 5. Nesse sentido categorizamos tanto as estratégias metodológicas citadas por elas, quanto os instrumentos que costumam utilizar dentro da metodologia. 
TABELA 5 - Estratégias e instrumentos utilizados para a inserção da EA após o Curso

\begin{tabular}{lc}
\hline Como estão trabalhando a EA nas aulas & Número de professoras que citaram \\
\hline Oficina temática & 5 \\
\hline Metodologia da Problematização & 5 \\
\hline Interpretação de gráficos e charges & 3 \\
\hline Construção de cartazes e fôlderes & 5 \\
\hline Pesquisas e vídeos
\end{tabular}

Fonte: Elaborada pelos autores

Como podemos observar, as professoras admitiram utilizar as metodologias abordadas no Curso de Formação e dentro destas, instrumentos que foram discutidos e planejados por elas como: interpretação de gráficos e charges, pesquisas e vídeos, sendo estes já utilizados pelas professoras antes do Curso de capacitação.

Ao compararmos as estratégias que as professoras utilizavam antes da realização do Curso (Tabela 3) com as que estão sendo desenvolvidas após a capacitação (Tabela 5), podemos constatar que houve uma modificação das mesmas, pois as docentes passaram a incluir a Metodologia de Oficinas Temáticas e a Metodologia da Problematização, as quais até então eram desconhecidas delas. Embora se observe o mantimento dos instrumentos por elas utilizados incluídos nas metodologias.

Ainda neste mesmo questionamento perguntamos se tinha ocorrido alguma mudança após participarem do Curso. As professoras relataram que foi um grande aprendizado que as motivou a seguirem com projetos que estavam em andamento.

A maioria das professoras relatou que o Curso de Formação oferecido superou as expectativas delas. A seguir apresentamos os aspectos positivos apontados por elas com relação à intervenção realizada:

\section{-Aspectos positivos:}

$\checkmark$ Boa explicação e Didática;

$\checkmark$ Proporcionou novos conhecimentos;

$\checkmark$ Tempo para interação, discussão e planejamento;

$\checkmark$ Compreensão do termo interdisciplinaridade.

Observamos que esses aspectos por elas citados foram fundamentais para o planejamento e aplicação (que ainda está sendo realizado) da Educação Ambiental neste 
ambiente escolar. Constatou-se que muitos professores já realizavam um trabalho interdisciplinar, mas apresentavam dúvidas e inseguranças. Os docentes não apontaram aspectos negativos do Curso, mas acreditamos que muitos procedimentos podem ser ajustados e melhorados para as próximas intervenções, como, por exemplo, utilizar-se mais de entrevistas não diretivas, pois a mesma demonstrou-se um eficaz instrumento de análise que possibilitou liberdade para os participantes demonstrarem suas vivências, experiências e perspectivas.

Freire (1980) enfatiza que para aprendermos necessitamos construir, reconstruir, constatar para mudar, o que não pode ser feito se não houver a abertura e correr-se o risco de tentarmos algo novo. Ainda de acordo com o autor, toda a prática educativa requer o envolvimento de sujeitos que aprendem e ensinam os conteúdos por meio de métodos, técnicas e materiais. O professor tem o papel de mediador entre o conhecimento sistematizado e as necessidades do aluno, e para que isto seja possível é necessário ter como base uma formação pautada em princípios interativos, tomando como referência as dimensões coletivas (FELDMANN, 2005).

Ao tratarmos da dimensão Educação Ambiental é indispensável que o professor saiba lidar com um conhecimento em construção, analisando a educação como um compromisso político, ético e moral. Por isso, o Curso que realizamos buscou abordar a dimensão ambiental de maneira interativa, considerando as experiências e resgatando o que já havia sendo realizado, de tal forma que possibilitasse uma transformação/construção de valores.

\section{CONCLUSÕES}

Buscamos desde o início auxiliar professores na inserção da EA por meio de uma perspectiva interdisciplinar que fosse significativa e se efetivasse em torno do contexto dos estudantes. Para isso, a estratégia elaborada neste estudo foi a realização de um Curso de Formação que visasse a capacitação dos profissionais na área da educação.

Neste contexto, acreditamos que nosso principal objetivo foi alcançado, visto que, por essa intervenção emergiu-se não apenas um plano de aula, mas um planejamento maior que foi e continuará sendo realizado dentro daquele ambiente escolar, propiciando: sensibilização e consciência ambiental; construção de conhecimentos; problematização e aquisição de valores.

Por meio dos resultados obtidos constatamos que, embora as professoras já trabalhassem com temas ambientais, as mesmas demonstraram ter insegurança e dificuldades de inserirem a EA tanto em suas disciplinas quanto de a abordar de maneira interdisciplinar.

Observou-se que surgiram novas estratégias de ensino utilizadas pelos docentes após o Curso, passando estes a adotar metodologias problematizadoras, distintas do paradigma 
tradicional, capazes de facilitar o ensino e contribuírem para uma efetiva inclusão da EA em sala de aula.

O desenvolvimento dos planos de aula permitiu que os sujeitos aplicassem o que haviam compreendido durante a realização do Curso, que ocorreu de maneira muito interativa, construtiva, possibilitando a troca de experiências das diferentes áreas do ensino.

Acreditamos que o problema ambiental é de natureza cognitiva e ética. Para tanto, é necessário trabalhar a construção de conhecimentos científicos, como os valores éticos e morais, visando a uma mudança destes (JÚNIOR, 2003). Por isso, acredita-se na importância de uma intervenção pedagógica, como a realizada neste estudo, aliada a uma orientação contínua que possibilite transformações no conhecimento, um (re)pensar e um (re)construir a prática docente.

Sendo assim, esta pesquisa nos proporcionou novos desafios e perspectivas para continuarmos buscando melhorias no ensino e na inclusão da EA de forma interdisciplinar. Articulando estratégias que são novas para determinada escola e/ou grupo de professores(as), bem como articular a participação da academia na busca pela melhoria da qualidade de ensino na escola pública e propiciar o desenvolvimento de cidadãos que tenham atuação sobre a sua realidade social, de modo a buscar melhorias e de reivindicar o bem-estar coletivo perante o poder público.

\section{REFERÊNCIAS}

BARDIN, Laurence. Análise de conteúdo. São Paulo: Edições 70, 2011, 229p.

BERBEL, Neusi Aparecida Navas. A Problematização e a Aprendizagem Baseada em Problemas: diferentes termos ou diferentes caminhos? Revista Interface: comunicação, saúde, educação, São Paulo, SP, v. 2. n. 2, p. 139-154, 1998c.

BRASIL. Secretaria do Ensino Fundamental. Parâmetros Curriculares Nacionais: Meio Ambiente. Brasília: MEC/SEF, 1997, 126p.

BRASIL. Secretaria de Educação Fundamental. Parâmetros Curriculares Nacionais. Brasília: MEC /SEF, 436 p,1998 b.

BRASIL. Ministério da Educação (SECAD/MEC). Cadernos SECAD. In: HENRIQUES, R. et al. (Org.). Educação ambiental: aprendizes de sustentabilidade. Brasília: MEC, 2007. 109p.

BRASIL. Lei Federal $\mathbf{n}^{\mathbf{0}}$ 12.305, de 2 de agosto de 2010. Institui a Política Nacional de Resíduos Sólidos; altera a Lei n 9.605 , de 12 de fevereiro de 1998; e dá outras providências. 
BRASIL. Lei de Diretrizes e Bases da Educação Nacional: Lei n ${ }^{\circ}$ 9.394, de 20 de dezembro de 1996, que estabelece as diretrizes e bases da educação nacional. 8.ed. Brasília: Câmera dos Deputados, Edições Câmeras, 2013.

BRASIL. Ministério do Meio Ambiente. Agenda 21. Disponível em: <http://www.mma.gov. br/responsabilidade-socioambiental/agenda-21>. 2001. Acesso em: 23 jul. 2014.

DIAZ BORDENAVE, Juan; PEREIRA, Adair Martins. Estratégias de ensinoaprendizagem. Petrópolis, RJ: Vozes, 2002.

CARVAlHO, Ana Maria Pessoa de; GIL PÉREZ, Daniel. Formação de professores de Ciências tendências e inovações. 10.ed. São Paulo, SP: Cortez, 2011. 128p.

CARVALHO, Isabel Cristina Moura. A invenção ecológica: narrativas e trajetórias da educação ambiental no Brasil. 2.ed. Porto Alegre: Ed. UFRGS, 2002.

CARVALHO, Isabel Cristina Moura. Qual educação ambiental? Elementos para um debate sobre educação ambiental e extensão rural. Agroecologia e Desenvolvimento Rural Sustentável, Porto Alegre, v.2, n.2, abr.jun. 2001.

FAZENDA, Ivani. Interdisciplinaridade - Transdisciplinaridade: visões culturais e epistemológicas. In: O que é interdisciplinaridade? São Paulo, SP: Cortez, 2008.

FREIRE, Paulo. Educação como prática da liberdade. Rio de Janeiro: Paz e Terra, 1980.

FREIRE, Paulo. Pedagogia da indignação: cartas pedagógicas a outros escritos. São Paulo: UNESP, 2000.

GALLO, Sílvio. Transversalidade e educação: pensando uma educação não-disciplinar. In: ALVES, Nilda e GARCIA, Regina Leite. (Org.). O sentido da escola. Rio de Janeiro: DP\&A, 1999. p.17-42

GARCIA, Maria de Fátima Lopes; LOURENCINI JÚNIOR, Álvaro; ZÔMPERO, Andréia de Freitas. Análise da metodologia da problematização utilizando temas da sexualidade: tendências e possibilidades. In: ENCONTRO NACIONAL DE PESQUISADORES EM EDUCAÇÃO EM CIÊNCIAS, 7., 2009, Florianópolis. Anais do... Florianópolis: ENPEC, Florianópolis, 2009.

LIBÂNEO, José Carlos. Didática. 2.ed. São Paulo, SP: Cortez, 1994.

MARCONDES, Maria Eunice Ribeiro. Proposições metodológicas para o ensino de Química: oficinas temáticas para a aprendizagem da Ciência e o desenvolvimento da cidadania. Em Extensão, Uberlândia, v. 7, n.1, p. 67-77, 2008. Disponível em: <http://www.seer.ufu.br/ index.php/revextensao/article/viewFile/20391/10861>. Acesso: 23 jun. 2014.

NARCIZO, Kaliane Roberta dos Santos. Uma análise sobre a importância de trabalhar educação ambiental nas escolas. Revista Eletrônica do Mestrado em Educação Ambiental, Rio Grande, v.2, p. 86-94, 2009. Disponível em: <http://www.seer.furg.br/remea/article/ view/2807/1585>. Acesso em: 25 de Jun. 2014. 
REIS JÚNIOR, Alfredo Morel dos. A formação do professor e a educação ambiental. 2003. 175 f. Dissertação (Mestrado em Educação) - Faculdade de Educação, Universidade Estadual de Campinas, Campinas, 2003.

SEVERINO, Antônio Joaquim. Metodologia do trabalho científico. 23.ed. rev. e atual. São Paulo, SP: Cortez, 2007.

TRISTÃO, Martha. A educação ambiental na formação de professores: redes de saberes. São Paulo; Vitória: Annablume/Facitec, 2004.

WOLLMANN, Ediane Machado; NICOLETTI, Elenize; SOARES, Félix Alexandre Antunes. Um estudo sobre as percepções de educação ambiental com acadêmicos e egressos do Curso de Química Licenciatura da UFSM. In: ENCONTRO DE DEBATES SOBRE O ENSINO DE QUÍMICA, 33., 2013, Ijuí. Anais do... Ijuí: EDEQ, 2013.

\section{Agradecimentos}

Aos docentes e à direção da escola onde ocorreu esta pesquisa por ter oportunizado este momento de trocas de saberes e aprendizado. Além disso, um agradecimento especial aos colegas do Grupo de Estudos em Nutrição, Saúde e Qualidade de Vida (GENSQ) da UFSM pelo auxílio no trabalho. À FAPERGS pelo apoio financeiro.

\section{Como citar este documento:}

WOLLMANN, Ediane Machado et al. A formação de professores para a inserção da prática ambiental: um relato de experiência. ETD - Educação Temática Digital, Campinas, SP, v. 16, n. 3, 532-550, set./dez. 2014. ISSN 1676-2592. Disponível em: <http://www.fe.unicamp.br/revistas/ged/letd/article/view/6895>. Acesso em: 23 dez. 2014. 